\title{
Polarized e-bunch acceleration at Cornell RCS: Tentative tracking simulations
}

\author{
F. Méot, V. Ptitsyn, V. Ranjbar, D. Rubin
}

\section{Collider-Accelerator Department Brookhaven National Laboratory Upton, NY 11973}

\author{
U.S. Department of Energy \\ Office of Science, Office of Nuclear Physics
}

Notice: This document has been authorized by employees of Brookhaven Science Associates, LLCunder Contract No. DE-SC0012704 with the U.S. Department of Energy. The United States Government retains a nonexclusive, paid-up, irrevocable, world-wide licenseto publish or reproduce the published form of this document, or allow others to do so, for United States Government purposes. 


\section{DISCLAIMER}

This report was prepared as an account of work sponsored by an agency of the United States Government. Neither the United States Government nor any agency thereof, nor any of their employees, nor any of their contractors, subcontractors, or their employees, makes any warranty, express or implied, or assumes any legal liability or responsibility for the accuracy, completeness, or any third party's use or the results of such use of any information, apparatus, product, or process disclosed, or represents that its use would not infringe privately owned rights. Reference herein to any specific commercial product, process, or service by trade name, trademark, manufacturer, or otherwise, does not necessarily constitute or imply its endorsement, recommendation, or favoring by the United States Government or any agency thereof or its contractors or subcontractors. The views and opinions of authors expressed herein do not necessarily state or reflect those of the United States Government or any agency thereof. 


\title{
Polarized e-bunch acceleration at Cornell RCS. Tentative tracking simulations
}

\author{
F. Méot ${ }^{\dagger}$, V. Ptitsyn ${ }^{\dagger}$, V. Ranjbar ${ }^{\dagger}$, D. Rubin ${ }^{\ddagger}$ \\ $\dagger$ Collider-Accelerator Department, BNL, Upton, NY 11973 \\ $\ddagger$ Cornell University, Ithaca, NY 14853
}

October 19, 2017

\begin{abstract}
An option as an injector into eRHIC electron storage ring is a rapid-cyclic synchrotron (RCS). Rapid acceleration of polarized electron bunches has never been done, Cornell synchrotron might lend itself to dedicated tests, which is to be first explored based on numerical investigations. This paper is a very preliminary introduction to the topic.
\end{abstract}

eRHIC Note 57

$B N L C-A D$

Sept. 2017 


\section{Contents}

1 Motivations 3

2 Cornell synchrotron $\quad \ldots$

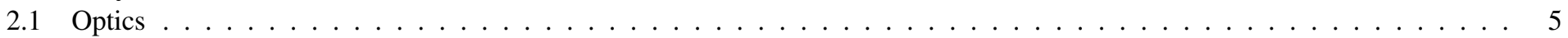

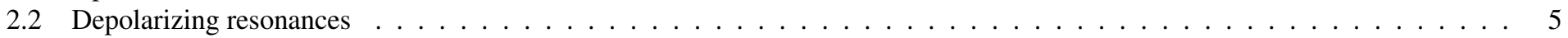

3 Polarization tracking, no SR 6

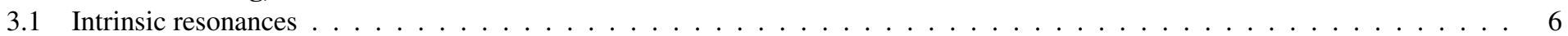

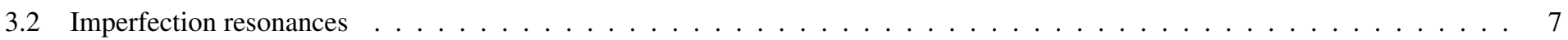

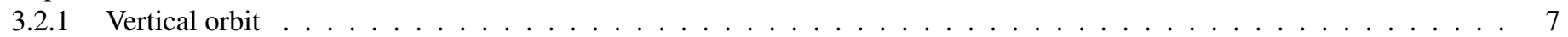

3.2 .2 Main bend roll $\ldots \ldots \ldots \ldots \ldots \ldots \ldots \ldots \ldots \ldots \ldots$

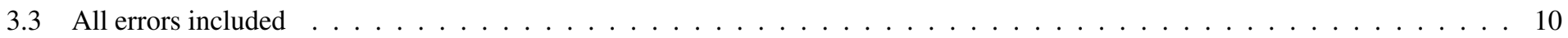

4 Polarization tracking, including SR 10

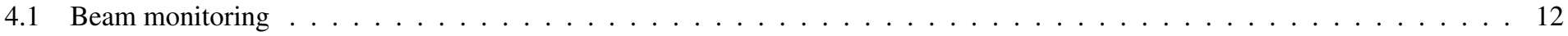

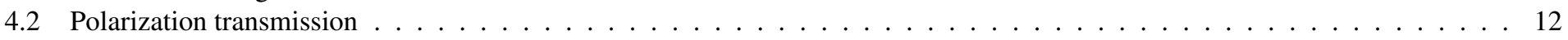

5 Comments 12

Acknowledgement

Appendix

A SBEND centering 13

B Benchmarking bunch motion 13

C Transverse motion at constant energy 14 


\section{Motivations}

An option as an injector into eRHIC electron storage ring is a rapid-cyclic synchrotron (RCS) [1], with a few tens of milliseconds acceleration cycle, this is under study [2]. However, it has been pointed out that rapid acceleration of polarized electron bunches has never been done and would deserve experimental investigation [3] :

"The RCS concept can be validated by simulations, but relevant experimental studies at Cornell would be helpful."

"Given the importance of the RCS, it is advisable that simulations are benchmarked to experimental results to be gathered at an existing facility. Such an experiment however would require at least a polarized source and two polarimeters."

The Cornell synchrotron ("RCS" in the following) seems to lend itself to such tests. However, possible proof-of-principle plans using it require numerical investigations in the first place, assessing in particular doable beam energy ranges including tolerances on field and alignment defects. A detailed study in this line would have to precede any further plans for an experiment.

This short report gives very preliminary and qualitative polarization tracking outcomes which confirm the principle of fast acceleration of a polarized electron bunch, using Cornell RCS nominal optics and RF conditions, and provide rough indications on tolerances on defects regarding polarization.

\section{Cornell synchrotron}

Table 1 lists the RCS parameters, it is used as the reference for the setup of the polarization transport simulation files in the next sections, details of the parameter values effectively used will be made clear in due place.

Table 1: Parameters of Cornell RCS. Simulations discussed here are based on this list.

\begin{tabular}{|c|c|c|c|}
\hline Injection energy & $\mathrm{MeV}$ & 320 & \\
\hline Top energy & $\mathrm{GeV}$ & $1.8-5.3$ & \\
\hline $\mathcal{C}$ & $\mathrm{m}$ & 755.87 & \\
\hline \multicolumn{4}{|l|}{ Bunch } \\
\hline Bunch charge & $\mathrm{nC}$ & 0.03 & \\
\hline Numb. of bunches/cycle & & 16 & \\
\hline Interval between bunches & $\mathrm{ns}$ & 14 & \\
\hline$\varepsilon_{\mathrm{x}}, \varepsilon_{\mathrm{y}}$, at $5.3 \mathrm{GeV}$ & $\mathrm{nm}$ & 400,110 & Normalized $(\mu \mathrm{m}): 4150,1140$ \\
\hline Bunch length & $\mathrm{mm}$ & 6 & \\
\hline Bunch $\mathrm{dE} / \mathrm{E}$ at injection, $5.3 \mathrm{GeV}$ & & $<1 \%, 2 \times 10^{-4}$ & \\
\hline \multicolumn{4}{|c|}{ Alternating gradient combined function lattice } \\
\hline Type & & FFDD & 48 periods \\
\hline Phase advance/period & $o$ & 75.4 & \\
\hline $\mathrm{Nb}$ of magnets & & 192 & 96 pairs \\
\hline Main field at $0.2 \mathrm{MeV}, 10,20 \mathrm{GeV}$ & $\mathrm{kG}$ & $0.02,3.3,6.6$ & \\
\hline $\operatorname{Max} . \beta_{\mathrm{x}}, \beta_{\mathrm{y}}$ & $\mathrm{m}$ & $25 \sim 30$ & \\
\hline $\mathrm{Q}_{\mathrm{x}}, \mathrm{Q}_{\mathrm{y}}$, typical & & 10.75 & \\
\hline$\xi_{\mathrm{x}}, \xi_{\mathrm{y}}$ & & -12 & \\
\hline \multicolumn{4}{|c|}{ The lattice includes two pairs of quads, one at LO and one at L3 straight sections } \\
\hline \multicolumn{4}{|l|}{ Longitudinal, $R F$} \\
\hline$f_{\text {rev }}$ & $\mathrm{kHz}$ & 396.6 & \\
\hline $\mathrm{f}_{\mathrm{rf}}$ & $\mathrm{MHz}$ & 713.94 & $\frac{1}{4}$ linac frequency $2855.76 \mathrm{MHz}$ \\
\hline $\mathrm{h}$ & & 1800 & \\
\hline $\mathrm{Nb}$ of accel. stations & & 4 & One station is enough for $5 \mathrm{GeV}$ \\
\hline repetition rate & $\mathrm{Hz}$ & up to 60 & Nominal is $60 \mathrm{~Hz}$ \\
\hline voltage/turn to $10 \mathrm{GeV}$ & $\mathrm{V}$ & 4.4 & in $\omega t+8.8 \sin ^{8} \frac{\omega t}{2}$ \\
\hline ramp duration to $5.3 \mathrm{GeV}$ & $\mathrm{ms}$ & 4.4 & \\
\hline \multicolumn{4}{|c|}{ Synchrotron radiation, radiation damping } \\
\hline$J_{x}=1-\mathcal{D}$ & & $<0$ & Radial motion is anti-damped \\
\hline$\tau_{\mathrm{SR}}\left(\approx 2.5 / E^{3}\right)$ at $5,10,15 \mathrm{GeV}$ & $\mathrm{ms}$ & $20,2,1$ & After Ref. [4] \\
\hline$\sigma_{x}$ at $10 \mathrm{GeV}, 15 \mathrm{GeV}$ & $\mathrm{cm}$ & 1,5 & \\
\hline
\end{tabular}




\section{Optical functions in Cornell RCS model}

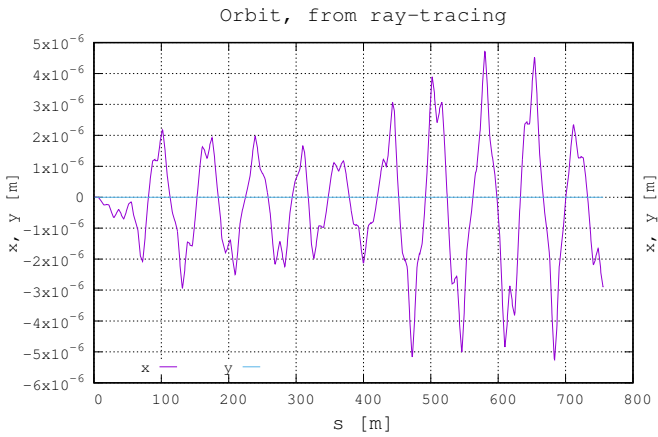

Figure 1: Residual horizontal orbit in the ray-tracing model of Cornell RCS. The vertical orbit is strictly zero.

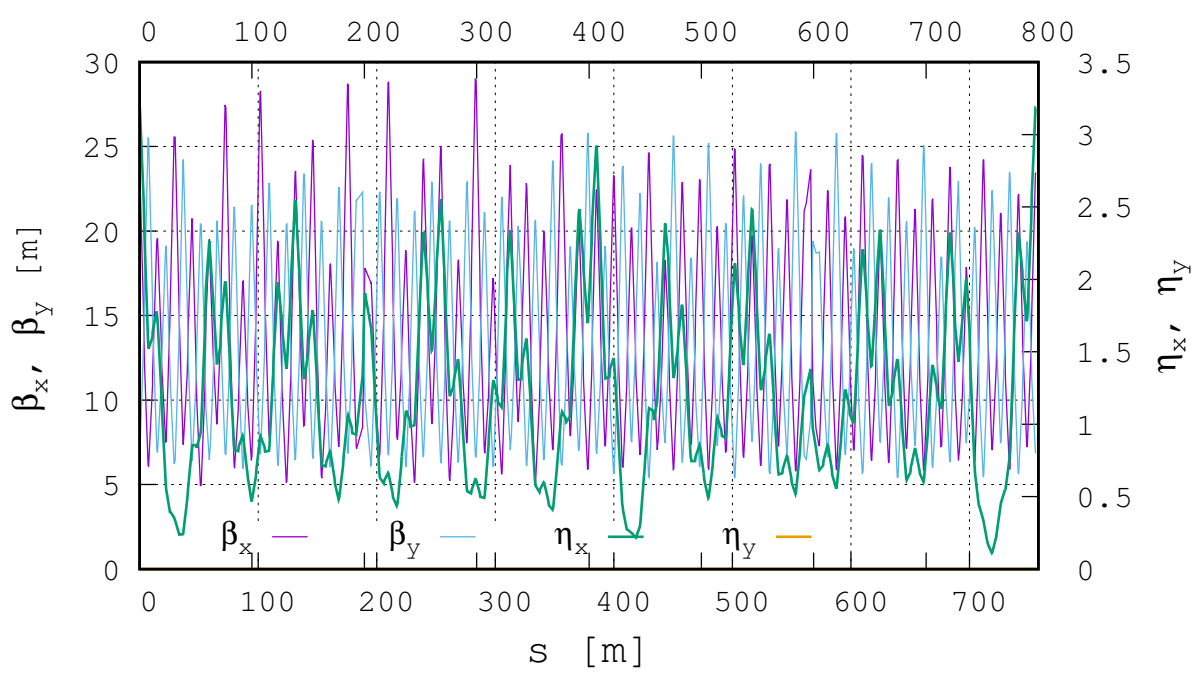

Figure 2: Betatron functions and dispersion.

\section{RF voltage ramp}

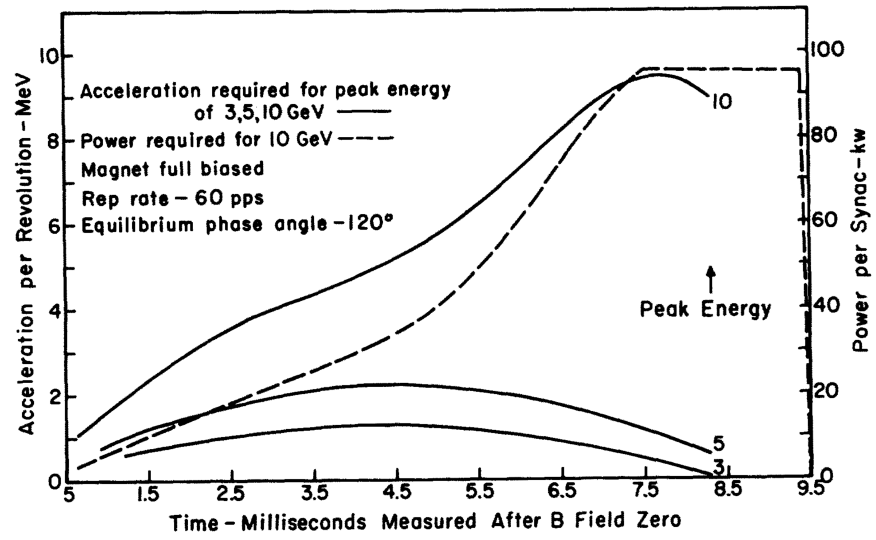

Fig. 1. Acceleration Required for Peak Energy of 3, $5,10 \mathrm{GeV}$.

Figure 3: Acceleration required for peak energy of 3, 5, $10 \mathrm{GeV}[4,5]$.
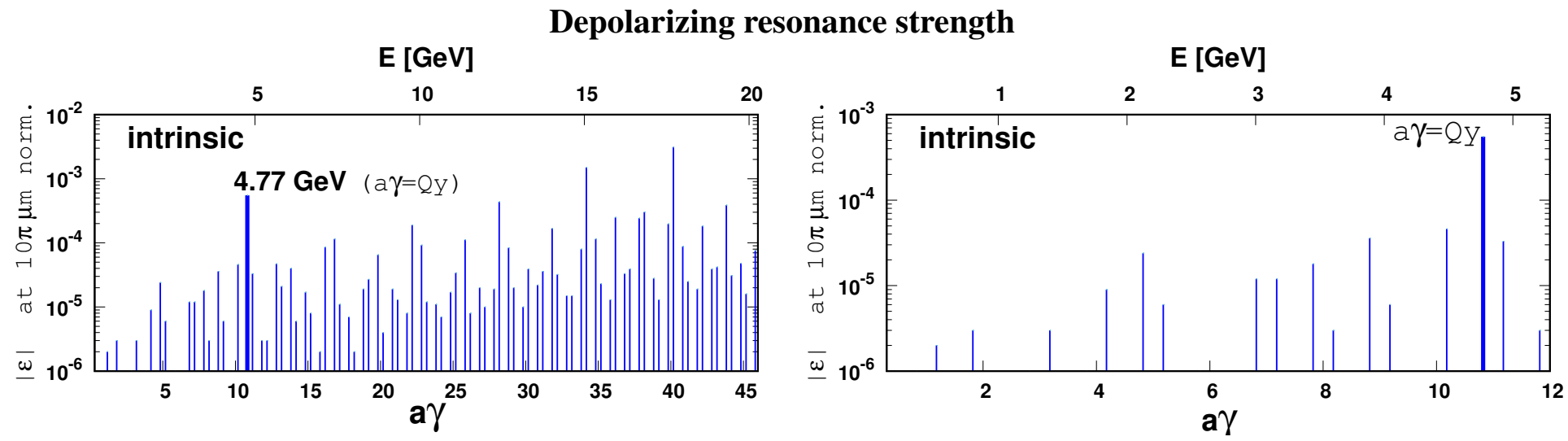

Figure 4: Strength of intrinsic resonances in the thin-lens model, for $\varepsilon_{\mathrm{y}}=10 \pi \mu \mathrm{m}$ normalized (the strength is proportional to $\sqrt{\epsilon_{\mathrm{y}}}$ ), with a zoom on the $0-5 \mathrm{GeV}$ region (right). The first strong intrinsic resonance is at a $\gamma=\mathrm{Q}_{\mathrm{y}}=10.82, \mathrm{E} \approx 4.77 \mathrm{GeV}$. Its strength at $10 \mu \mathrm{m}$, normalized, is $5 \times 10^{-4}\left(5 \times 10^{-3}\right.$ at nominal $1000 \mu \mathrm{m}$ normalized, $\left.5 \mathrm{GeV}\right)$. 


\subsection{Optics}

Cornell RCS sequence for bunch polarization tracking [6] has been translated from the MAD model.

Given appropriate radial offset of the six different families of combined function bends in their stepwise ray-tracing model, the residual periodic orbit is zero. That offset is required because of the arc of circle trajectory in the straight axis "MULTIPOLE" model used. In addition, it is obtained using a fitting procedure as the trajectory across the combined function bend experiences a non-constant field (see App. A).

Basic optics outcomes are displayed in Tab. 2 and in Figs. 1,2. These paraxial data appear to be practically identical in the two models, MADX and ray-tracing.

Table 2: Some RCS model optical parameters in MADX and ray-tracing models, to establish the present working hypotheses.

\begin{tabular}{|c|c|c|}
\hline \multicolumn{3}{|c|}{$\diamond$ Ray-tracing } \\
\hline a & LENGTH & $\div 1$ \\
\hline @ & ALFA & $\% 1$ \\
\hline (]) & ORBIT 5 & $\div 1$ \\
\hline e & GAMMATR & $\div 1$ \\
\hline Q & $\mathrm{Q} 1$ & $\circ$ \\
\hline Q & $\mathrm{Q} 2$ & $\div]$ \\
\hline e & $\mathrm{DQ1}$ & \\
\hline @ & $\mathrm{DQ} 2$ & \\
\hline e & DXMAX & \\
\hline e & DYMAX & \\
\hline a & XCOMAX & \\
\hline Q & YCOMAX & \\
\hline a & BETXMAX & \\
\hline Q & BETYMAX & \\
\hline Q & DXRMS & \\
\hline & DYRMS & \\
\hline
\end{tabular}
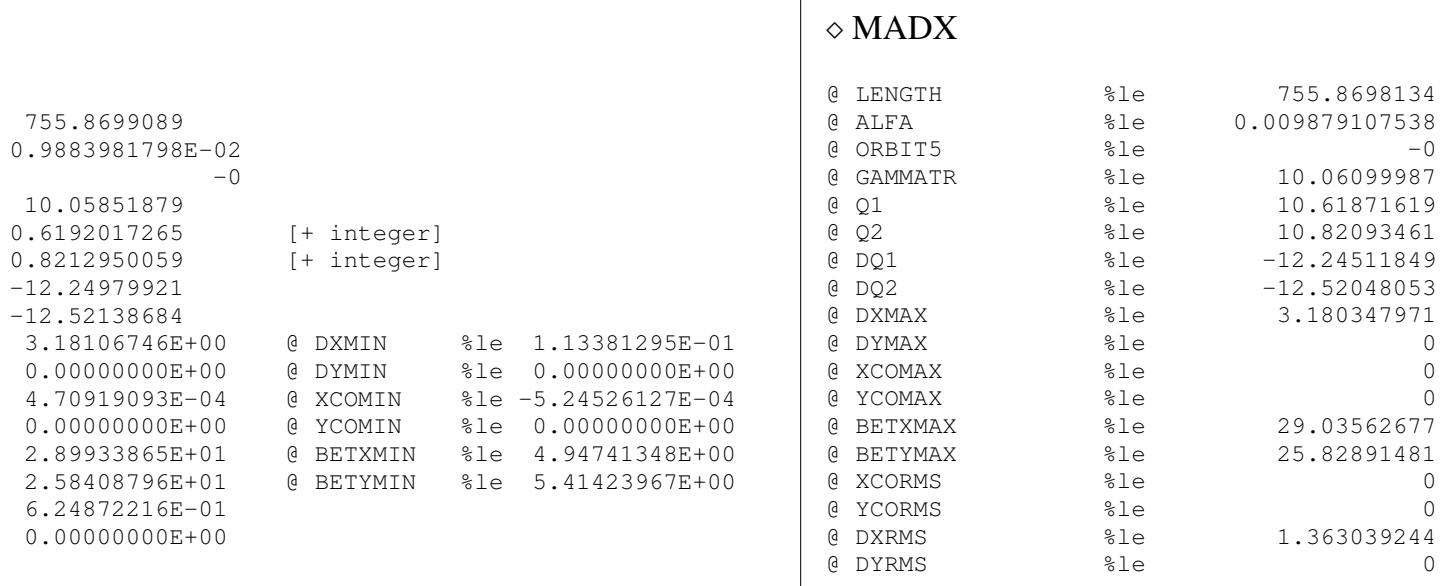

$\diamond$ Radiation integrals, from MAD :

$\begin{array}{ccccc}\text { I1 } & \text { I2 } & \text { I3 } & \text { (C) I 4 } & \text { I5 } \\ 7.4654 \mathrm{E}+00 & 6.4224 \mathrm{E}-02 & 6.5647 \mathrm{E}-04 & 1.2469 \mathrm{E}-01 & 1.0896 \mathrm{E}-04\end{array}$

\subsection{Depolarizing resonances}

- Intrinsic resonances. Figure 4 shows the strength of intrinsic resonances (of the form a $\chi \pm \mathrm{Q}_{\mathrm{y}}=$ integer) in a $0<$ a $\gamma<50$ range $(.2<\mathrm{E}<22 \mathrm{GeV})$. They are calculated in the thin-lens model, namely

$$
\epsilon^{ \pm}=\frac{1+\mathrm{a} \gamma}{4 \pi} \Sigma_{\text {Qpoles }}\left\{\begin{array}{c}
\cos \left(\mathrm{a} \gamma \alpha_{\mathrm{i}} \pm \psi_{\mathrm{i}}\right) \\
+\mathrm{i} \sin \left(\mathrm{a} \gamma \alpha_{\mathrm{i}} \pm \psi_{\mathrm{i}}\right)
\end{array}\right\}(\mathrm{KL})_{\mathrm{i}} \sqrt{\beta_{\mathrm{y}, \mathrm{i}} \varepsilon_{\mathrm{y}} / \pi}
$$

a summation over quadrupoles around the ring, with $(\mathrm{KL})_{\mathrm{i}}$ the strength of quadrupole number $\mathrm{i}, \alpha_{\mathrm{i}}$ the orbital angle, $\beta_{\mathrm{y}, \mathrm{i}}$ the vertical betatron function value (taken from the ray-tracing model, Fig. 2), $\psi_{\mathrm{i}}=\int_{0}^{\theta_{\mathrm{i}}} \frac{\mathrm{ds}}{\beta_{\mathrm{y}}}$ the betatron phase advance, and ' \pm ' sign for respectively $\mathrm{a} \gamma \pm \mathrm{Q}_{\mathrm{y}}-\mathrm{n}=0, \mathrm{n}$ integer.

Numerical simulations to follow will yield insights, however a first estimate of the effect of the depolarizing resonances can be obtained as follows. Assume the strongest resonance crossed is that at $a \gamma=21-Q_{y} \approx 10.18$ just preceding $a \gamma=0+Q_{y} \approx 10.82$ (Fig. 4),

- take $\varepsilon_{\mathrm{y}, \mathrm{N}}=10^{4} \pi \mu \mathrm{m}$ normalized invariant value at $\approx 4.5 \mathrm{GeV}$ (large excursion particles, 10 times the nominal rms bunch emittance, see Tab. 2),

- thus the experienced strength is $|\epsilon| \approx 510^{-5} \sqrt{10^{3}} \approx 1.510^{-3}$ (normalized from the $\varepsilon_{\mathrm{y}, \mathrm{N}}=10 \pi \mu \mathrm{m}$ strength, $a \gamma=10.2$ region, Fig. 4), - take for the crossing speed $\alpha=\frac{\mathrm{a}}{2 \pi} \frac{\mathrm{dE}}{\mathrm{M}} \quad\left(\mathrm{a}=1.15965213627 \times 10^{-3}, \mathrm{M}=0.511 \mathrm{MeV}\right)$, at $4.5 \mathrm{GeV}$, from the $\mathrm{RF}$ energy gain $\mathrm{dE} \mathrm{RF}_{\mathrm{RF}} \approx$ $+3 \mathrm{MeV}$, and from synchrotron radiation (SR) energy loss $\mathrm{dE}_{\mathrm{SR}}=-0.0885 \frac{\mathrm{E}_{[\mathrm{GeV}]}^{4}}{\rho_{[\mathrm{m}]}} \approx-0.5 \mathrm{MeV}$ (with $\rho \approx 100 \mathrm{~m}$ ), thus $d E=d E_{R F}+$ $d E_{S R}=2.5 \mathrm{MV} /$ turn, which all in all yields $\alpha \approx 10^{-3}$.

One then gets the ratio of final to initial polarization upon crossing such resonance,

$$
\frac{\mathrm{P}_{\mathrm{f}}}{\mathrm{P}_{\mathrm{i}}}=2 \exp \left(-\frac{\pi}{2} \frac{|\epsilon|^{2}}{\alpha}\right)-1 \approx 0.993
$$

an encouraging result given that the few upstream resonances all are weaker, Fig. 4.

An upper limit of the cumulated effect of the intrinsic resonance series from injection to a $\gamma<\mathrm{Q}_{\mathrm{y}}$ can be derived in the following way :

Crossing a N-series of resonances, $1,2,3, \ldots \mathrm{N}$, results in the final $P_{f, N}$ (next to the N-th resonance) to initial $P_{i, 1}$ (before the i-th resonance) polarization ratio

$$
\frac{\mathrm{P}_{\mathrm{N}, \mathrm{f}}}{\mathrm{P}_{1, \mathrm{i}}}=\frac{\mathrm{P}_{\mathrm{N}, \mathrm{f}}}{\mathrm{P}_{\mathrm{N}, \mathrm{i}}} \times \frac{\mathrm{P}_{\mathrm{N}-1, \mathrm{f}}}{\mathrm{P}_{\mathrm{N}-1, \mathrm{i}}} \ldots \times \frac{\mathrm{P}_{1, \mathrm{f}}}{\mathrm{P}_{1, \mathrm{i}}}
$$


given that, for all $\mathrm{j}, P_{j, i} \equiv P_{j-1, f}$. Now, as $\mathrm{P}_{\mathrm{f}} / \mathrm{P}_{\mathrm{i}} \approx 1$, take $\exp \left(-\pi|\epsilon|^{2} / 2 \alpha\right) \approx 1-\pi|\epsilon|^{2} / 2 \alpha$ and so $\mathrm{P}_{\mathrm{f}} / \mathrm{P}_{\mathrm{i}} \approx 1-\pi|\epsilon|^{2} / \alpha$. The relation above thus yields

$$
\frac{\mathrm{P}_{\mathrm{N}, \mathrm{f}}}{\mathrm{P}_{1, \mathrm{i}}} \approx\left(1-\frac{\pi\left|\epsilon_{\mathrm{N}}\right|^{2}}{\alpha_{\mathrm{N}}}\right) \times \ldots \times\left(1-\frac{\pi\left|\epsilon_{2}\right|^{2}}{\alpha_{2}}\right) \times\left(1-\frac{\pi\left|\epsilon_{1}\right|^{2}}{\alpha_{1}}\right) \approx 1-\sum_{\mathrm{j}=1, \mathrm{~N}} \frac{\pi\left|\epsilon_{\mathrm{j}}\right|^{2}}{\alpha_{\mathrm{j}}}
$$

with $\left|\epsilon_{\mathrm{j}}\right|$ and $\alpha_{\mathrm{j}}=\mathrm{da} \gamma_{\mathrm{j}} / \mathrm{d} \theta$ respectively the strength of, and crossing speed at resonance $\mathrm{j}$. The ingredients needed to estimate this are,

- the acceleration rate $\alpha_{\mathrm{j}}=\mathrm{da} \gamma_{\mathrm{j}} / \mathrm{d} \theta$, about $10^{-3} \sim 310^{-3}$ over $0.6 \sim 4.8 \mathrm{GeV}$ (the lower energy resonance in Fig. 4 is at $\approx 1.2 \mathrm{GeV}$ ),

- the resonance strength, which scales with $1+a \gamma$ (assuming constant geometrical $\epsilon_{y}$, Eq. 1),

- and the time-dependent RF voltage and energy loss, which determine the turn-by-turn energy gain.

However, even in the pessimistic hypothesis that, for all $\mathrm{j},\left|\epsilon_{\mathrm{j}}\right|=1.510^{-3}$ and $\alpha_{j}=10^{-3}$, a series of 10 such resonances would yield (Eq. 3)

$$
\frac{\mathrm{P}_{\mathrm{a} \gamma=\mathrm{Q}_{\mathrm{y}}^{-}}}{\mathrm{P}_{\text {injection }}} \approx 0.93
$$

- Imperfection resonances. They satisfy a $\gamma=$ integer, their strength can be calculating using

$$
\epsilon=\frac{1+\mathrm{a} \gamma}{2 \pi} \Sigma_{\text {Qpoles }}\left\{\begin{array}{c}
\cos \left(a \gamma \alpha_{i}\right)+ \\
\mathrm{i} \sin \left(\mathrm{a} \gamma \alpha_{\mathrm{i}}\right)
\end{array}\right\}(\mathrm{KL})_{\mathrm{i}} \mathrm{y}_{\mathrm{co}, \mathrm{i}}
$$

However they are $y_{c o, i}$ dependent (orbit amplitude at each quadrupole), thus their assessment will be postponed to numerical simulations including random vertical orbit defects, next Sections.

\section{Polarization tracking, no SR}

In this Section we review basic outcomes of resonance crossing, in the presence of large betatron motion in a defect-free lattice first, and in the presence of orbit imperfections next.

It will come out of these preliminary simulations that, as expected from Sec. 2.2, intrinsic resonances are essentially harmless considering the emittances at Cornell RCS (the resonance strength parameter $|\epsilon|^{2} / 8 \alpha$ is below $10^{-2}$ in the energy range of interest for that experiment, up to $10 \mathrm{GeV}$ about, leading to preservation of polarization close to $100 \%$ ).

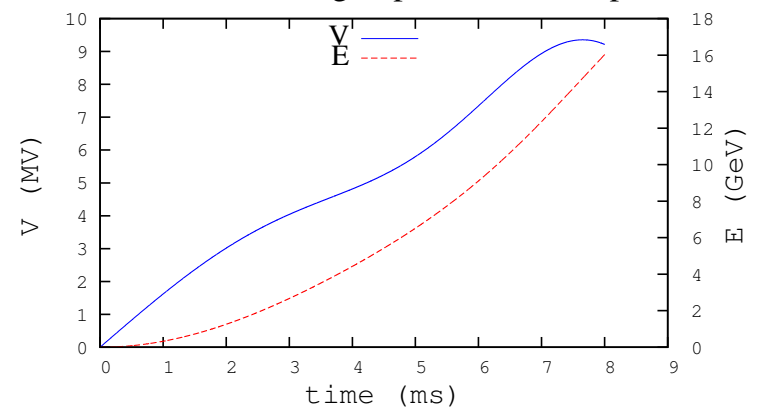

$\diamond$ Accelerating cavity data :

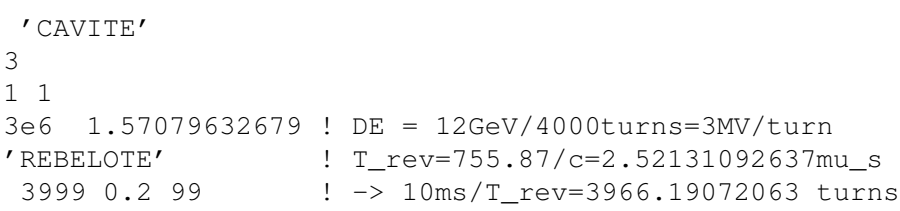

Figure 5: Applied accelerating voltage and resulting bunch energy.

The simplified simulation conditions in this Section are the following :

- a set of 17 particles are tracked, all launched on the same invariants $\varepsilon_{\mathrm{x}} \approx 0, \varepsilon_{\mathrm{y}} / \pi=0.25$ or $25 \mu \mathrm{m}$ geometrical $\left(\varepsilon_{\mathrm{y}} / \pi=10^{2}\right.$ or $10^{4} \mu \mathrm{m}$ normalized),

- different types of defects are considered, specified in due place,

- the acceleration voltage applied is (Fig. 5)

$$
\mathrm{V}(\mathrm{t})=4.4 \sin (2 \pi \mathrm{ft})+8.8 \sin ^{8}(2 \pi \mathrm{ft} / 2), \quad \mathrm{f}=60 \mathrm{~Hz}
$$

- the tracking uses a Monte Carlo SR process [7],

Some of the input data to the tracking code are added in the text, for the simulation conditions to be clear, and reproducible.

\subsection{Intrinsic resonances}

This preliminary tracking aims at establishing the basis tracking conditions, and in passing confirming Sec. 2.2. A defect-free ring is considered, vertical betatron motion is the potential source of depolarization, by intrinsic resonances.

The invariant used here is determined as follows : the normalized vertical emittance is $1140 \mu \mathrm{m}$ at $5.3 \mathrm{GeV}$ (Tab. 1). Ignoring SR effects that yields $1140 / 391 \approx 2.9 \mu \mathrm{m}$ at injection $(200 \mathrm{MeV})$. Large excursion particles are considered, an invariant 9 times that value, $\varepsilon_{\mathrm{y}} / \pi=25 \mu \mathrm{m}$ 
geometrical. Spin tracking results are displayed in Fig. 6. The depolarization through the resonance $a \gamma=Q_{y}=10.82$ amounts to an average $P_{f} / P_{i} \approx 0.1$, which results from the large invariant considered. This is consistent with the following quantities :

$$
\varepsilon_{\mathrm{y}, \mathrm{N}} / \pi=10 \mathrm{~mm} \text {, resonance strength }|\epsilon|=1.510^{-3} \text {, acceleration rate } \Delta \mathrm{E} \approx 2 \mathrm{MV} / \text { turn. }
$$

Particle coordinates in Zgoubi :

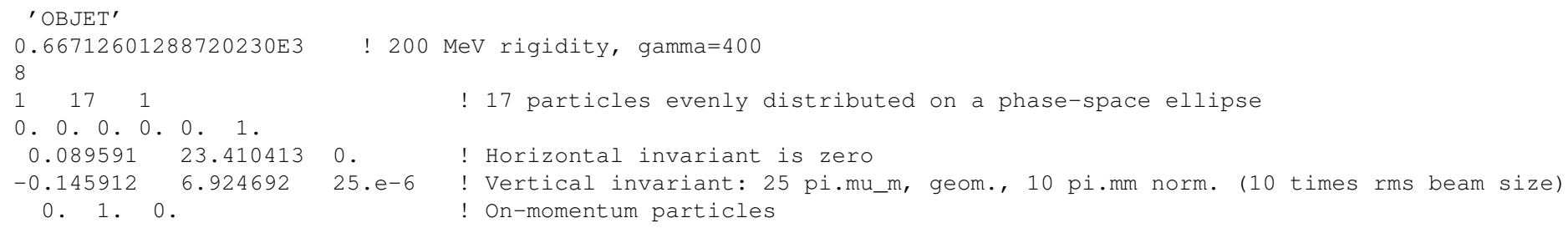

\section{$\mathrm{K} 1$ defect in $\mathrm{CF}$ bends}

A contrario, we make sure here that a gradient defect in the CF dipoles (which will contribute horizontal orbit and beta-beat) has marginal effect on the polarization. This is confirmed in Fig. 7.

- OBJET and ERRORS command data for Fig. 7 (17 particles evenly on $100 \pi$ invariant, dK1/K1 $\in \pm 1 \%$ (random, uniform) in all main bends) :

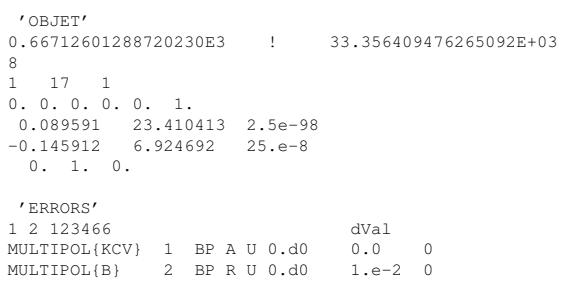

- Optics, from ray-tracing :
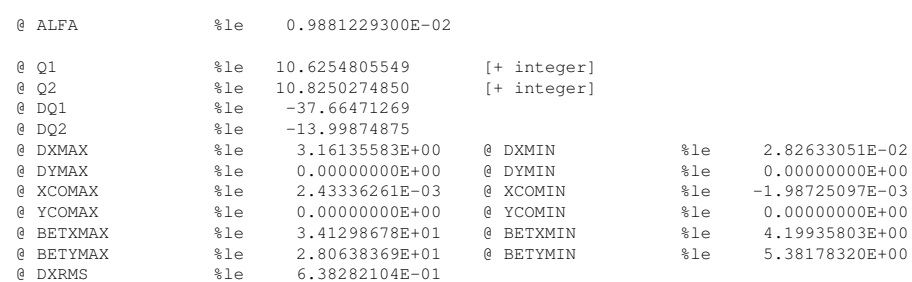

"MULTIPOL $\{B\}$ ” stands for the 200 main bends found in the RCS lattice. The optics is perturbed by random, uniform dK1 in these bends.

The table above to the right gives the perturbed optics, for comparison with the unperturbed case page 5 .

\subsection{Imperfection resonances}

Random kicks in vertical correctors (a similar effect to vertical displacement of the CF function dipoles) and roll angle are the two types of defects considered. Only one random seed will be thrown, no statistics is performed in this preliminary approach.

Various vertical orbit amplitudes considered, commensurate with orbit records at Cornell RCS, Fig. 9.

\subsubsection{Vertical orbit}

Vertical orbit is created with a random field in the 46 vertical kickers. The vertical invariant is taken small (100 $\pi \mu \mathrm{m}$ norm.), for the imperfection resonances to dominate.

- OBJET and ERRORS command data for Fig. 8 (17 particles evenly on $100 \pi$ invariant, either $\pm 0.6, \pm 1.2$ or $\pm 2.5 \mathrm{~mm}$ rms orbit) :

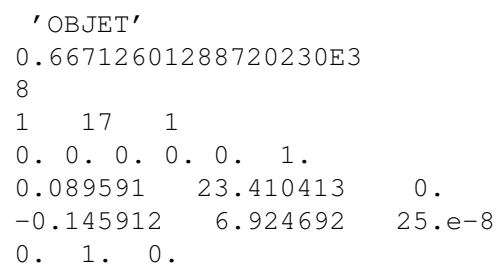

"MULTIPOL $\{\mathrm{KCV}\}$ " sprinkle kicks at random in the $46 \mathrm{~V}$-kickers found in the RCS lattice. Kicks are taken in a uniform distribution, to create vertical orbits of rms amplitude $0.6,1.2$ or $2.5 \mathrm{~mm}$.

The orbit has a strong betatron-frequency Fourier component, it can be removed in a refined approach.

\subsubsection{Main bend roll}

Defect orbit is induced here by a random roll of the dipole component in the CF dipoles. The amplitude of the effect is illustrated in Fig. 10. Fig. 11 shows the resulting crossing through a $\gamma=$ integer resonances up to $7.3 \mathrm{GeV}$, for three different sets of random $\mathrm{K}_{0}$ rolls, taken in a uniform distribution, respectively in the interval $\pm 0.02, \pm 0.1$ or \pm 1 degree. 

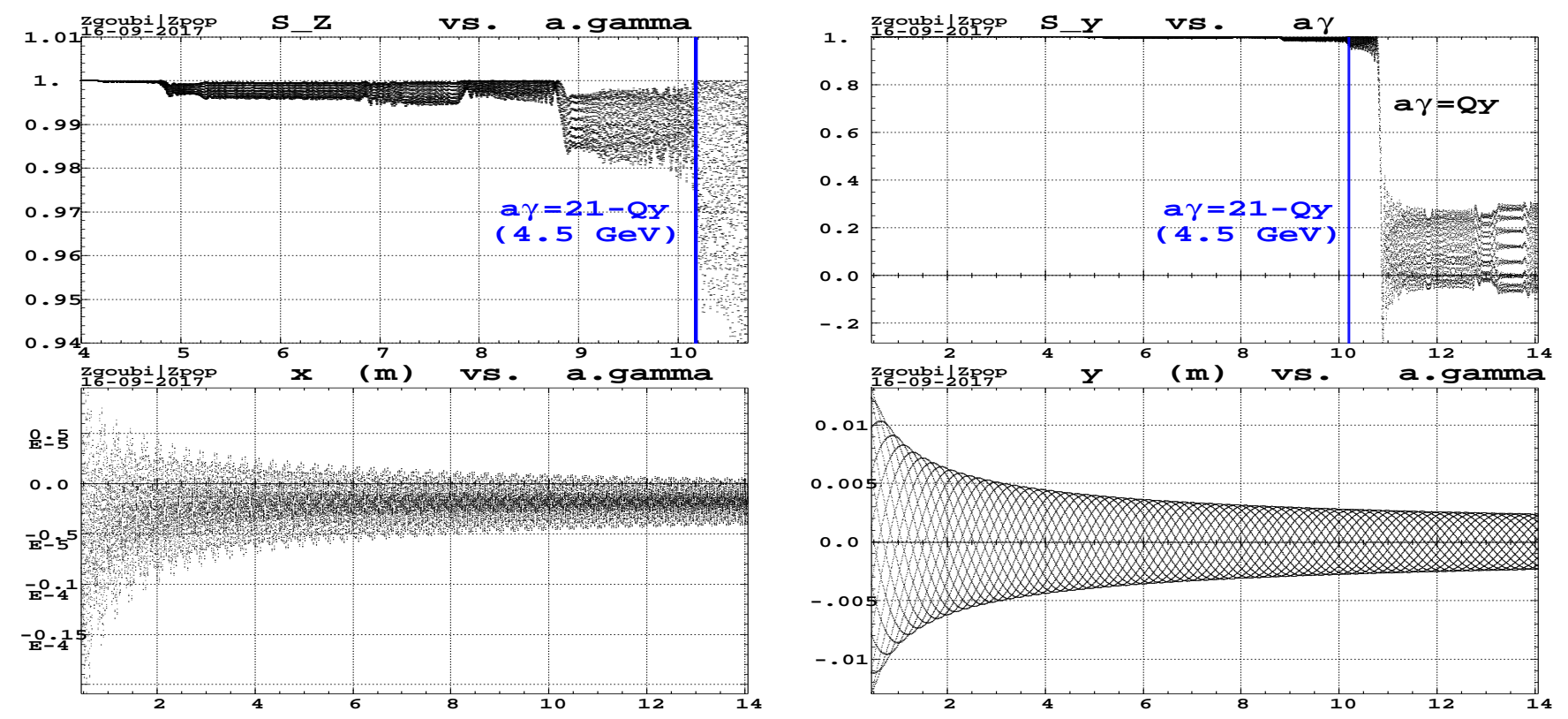

Figure 6: A defect-free ring is considered here. Top row : evolution of the vertical component of the spin of 17 particles launched on a 9-rms invariant, up to $7.3 \mathrm{GeV}$, the figure on the left is a zoom on the $a \gamma=21-Q_{y}$ region. Bottom row, left : the horizontal motion is taken quasi-zero : right : the vertical motion features betatron damping.
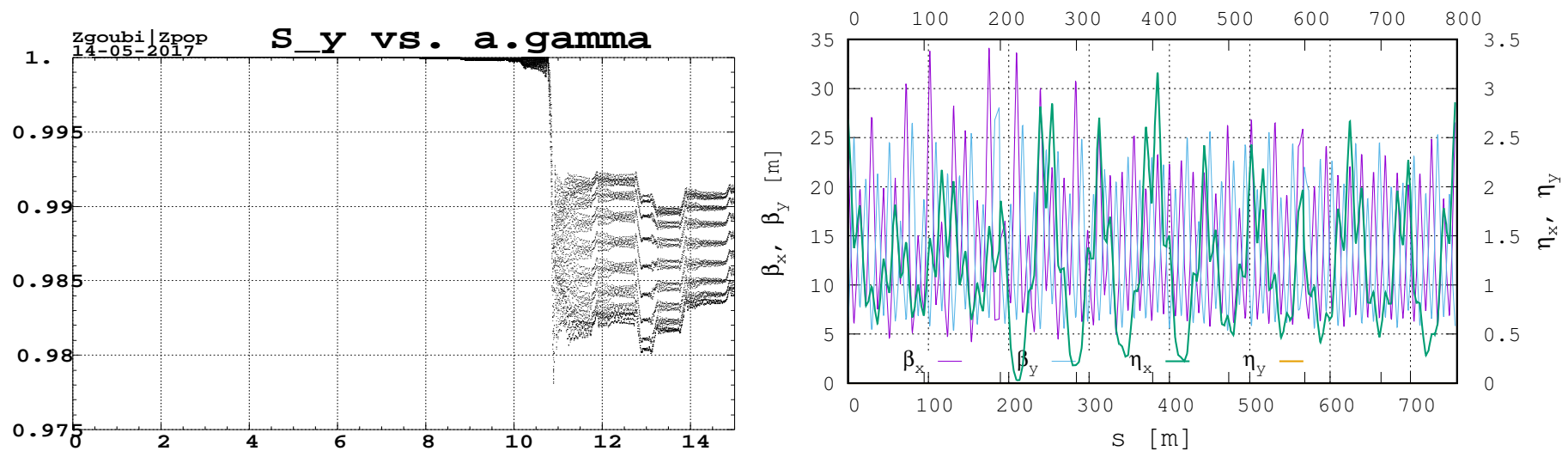

Figure 7: K1 error in bends. 17 particles, evenly on invariant $\varepsilon_{\mathrm{y}} / \pi=100 \mu \mathrm{m}$ normalized. K1 error is $\pm 1 \%$ random uniform in all main bends. The right plot shows the optical functions so obtained, for comparison with Fig. 2.

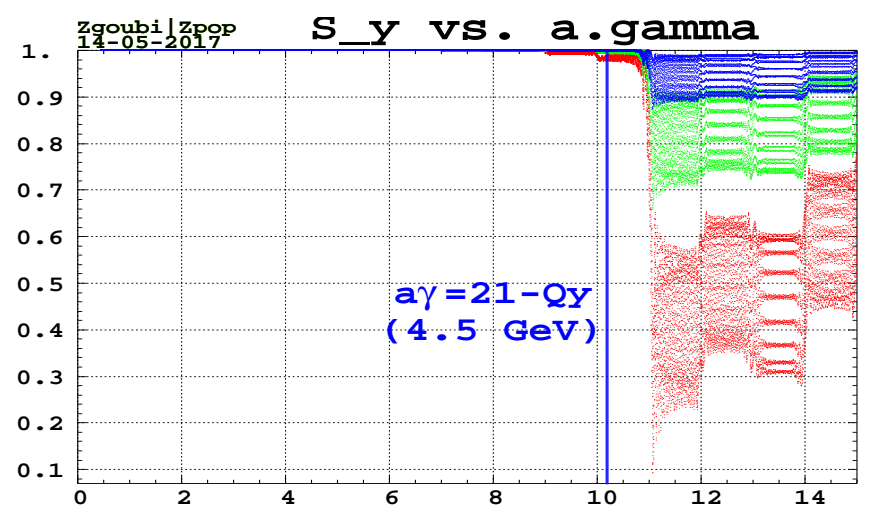

Figure 8: Vertical orbit defect, 17 particles, evenly on invariant $\varepsilon_{\mathrm{y}} / \pi=100 \mu \mathrm{m}$ normalized. Three different $r m s$ orbit amplitudes considered (orbit source is random uniform kick in 46 vertical kickers) : $0.6,1.2$ and $2.5 \mathrm{~mm}$. 

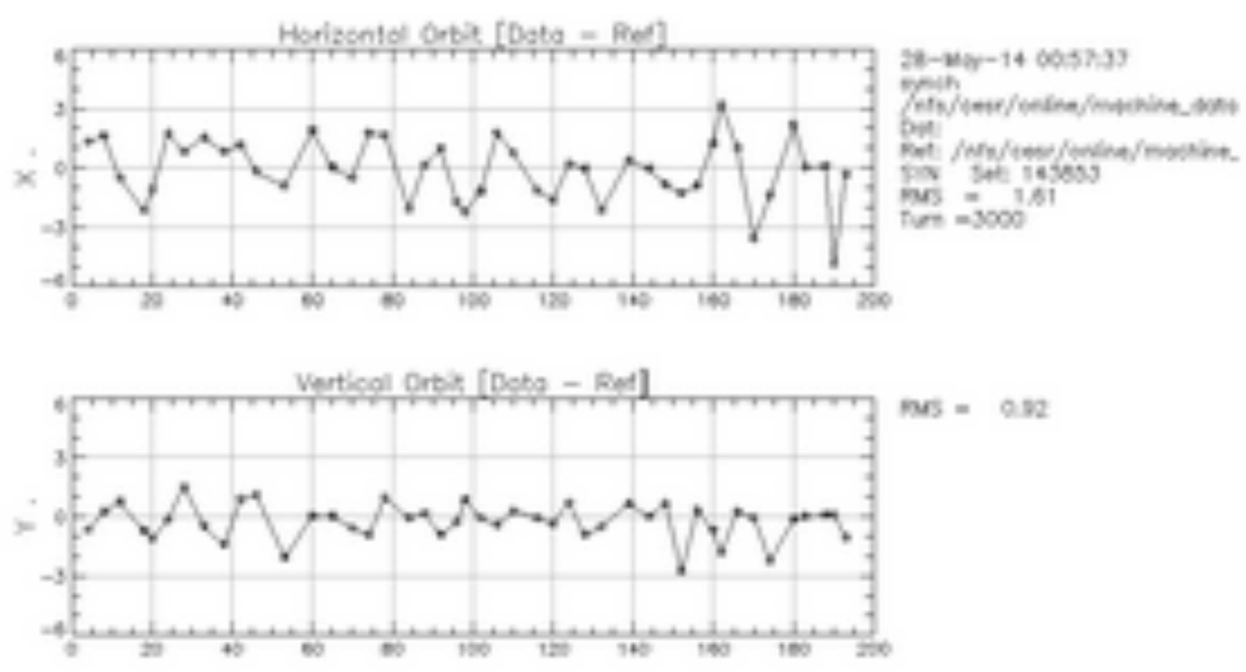

Muknow notet fruetal

Figure 9: Sample orbit records at Cornell RCS. It gives an indication of orbit control achieved, $1.61 \mathrm{~mm}$ horizontal, $0.92 \mathrm{~mm}$ vertical $\mathrm{rms}$ in this particular case. Vertical orbit defects for exploration of effects on spin in the present simulations will be pushed to comparable or slightly higher values.

- The ERRORS command data for Fig. $11, \mathrm{~K}_{0}$ roll $\in \pm 1^{\circ}$ (random, uniform) at all main bends :

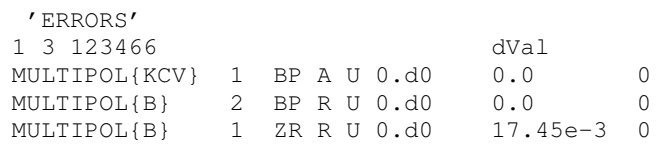

"MULTIPOL $\{B\}$ " stands for the 200 main bends found in the RCS lattice.

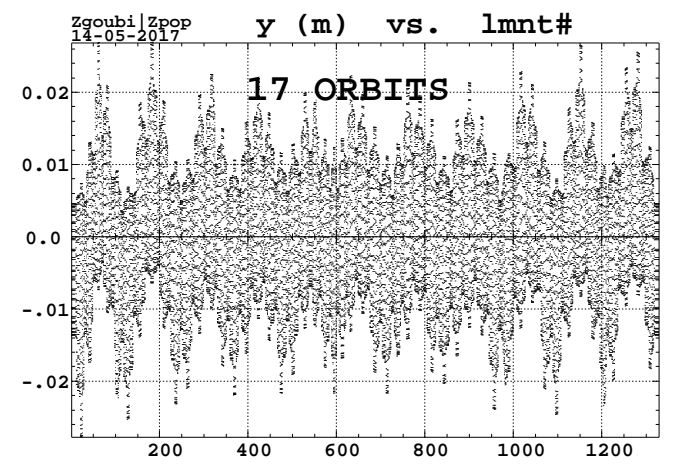

Figure 10: A $10 \mathrm{~mm}$ rms vertical orbit induced by a 0.1 deg random $\mathrm{K}_{0}$ roll error in the main bends.
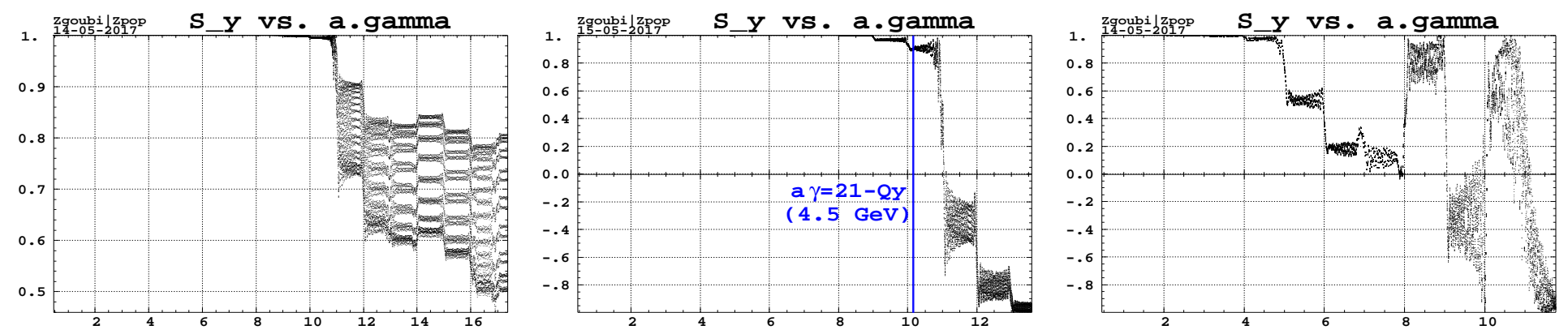

Figure 11: $\mathrm{K}_{0}$ roll at all main bends. 17 particles, evenly on invariant $\varepsilon_{\mathrm{y}} / \pi=100 \mu \mathrm{m}$ normalized. $\mathrm{K}_{0}$ roll angle $\in \pm 0.02^{\circ}\left(\right.$ left), $\in \pm 0.1^{\circ}$ (middle), $\in \pm 1^{\circ}$ (right), random uniform. 


\subsection{All errors included}

- The OBJET and ERRORS command data for Fig. 12 :

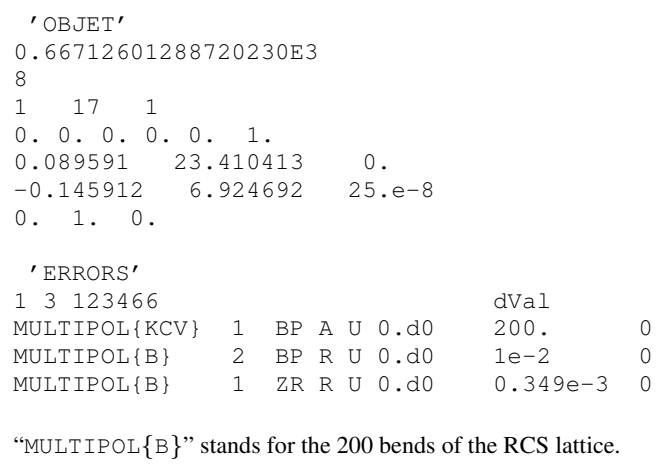

"MULTIPOL $\{B\}$ " stands for the 200 bends of the RCS lattice.

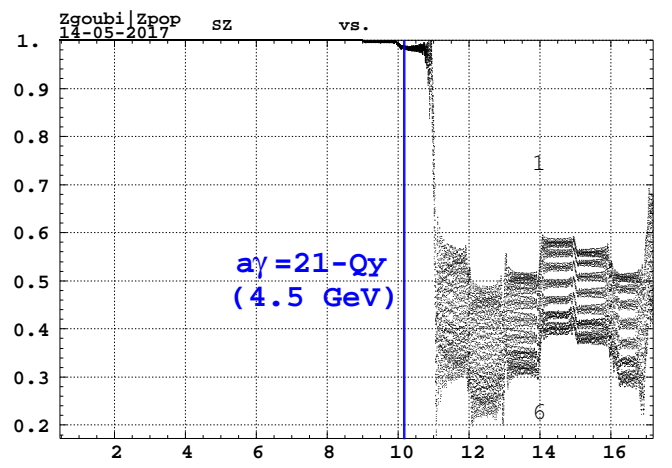

Figure 12: Errors include $1.2 \mathrm{~mm}$ rms orbit contribution from the 46 vertical kickers, $\mathrm{dK} 1 / \mathrm{K} 1 \in \pm 1 \%$ in all main bends, $\mathrm{K}_{0}$ roll $\in \pm 0.02^{\circ}$ in all main bends, all random uniform. 17 particles, launched evenly on invariant $\varepsilon_{\mathrm{y}} / \pi=100 \mu \mathrm{m}$ normalized.

\section{A summary of these preliminary outcomes}

The Table below summarizes the outcomes of these elementary tracking simulations, for the different error conditions explored in the previous sections. Only for unrealistically large orbit deviation does the depolarization become significant.

Table 3: Average polarization at a $\gamma=10.2$ $(\mathrm{E}=4.5 \mathrm{GeV})$, depending on defect type.

\begin{tabular}{|c|c|c|}
\hline $\begin{array}{l}\text { orbit defect, } \\
\text { type and value }\end{array}$ & $\begin{array}{c}\text { final } \\
\text { polarization }\end{array}$ & comment \\
\hline \multicolumn{3}{|c|}{$\begin{array}{l}\epsilon_{\mathrm{y}, \mathrm{N}} / \pi=10 \mathrm{~mm} \\
\text { none } \\
d K 1 / K 1 \text { in } C F \text { bends, } 1 \% \text { relative, } \epsilon_{\mathrm{y}, \mathrm{N}} / \pi=100 \mathrm{mum} \\
\text { none } \quad 0.9997\end{array}$} \\
\hline $\begin{array}{l}\text { Vertical kickers } \\
0.6 \mathrm{~mm} \\
1.2 \mathrm{~mm} \\
2.5 \mathrm{~mm}\end{array}$ & $\begin{array}{r}\delta \mathrm{y}_{\mathrm{rms}} \\
0.999 \\
0.996 \\
0.983\end{array}$ & \\
\hline $\begin{array}{l}\text { Main bend: } \mathrm{K}_{0} \\
0.02 \text { deg. } \\
0.1 \mathrm{deg} . \\
1 \mathrm{deg} .\end{array}$ & $\begin{array}{l}\text { roll } \\
\qquad 0.995 \\
0.905 \\
\text { depolarized }\end{array}$ & $\begin{array}{l}\text { induced rms V orbit } 1.3 \mathrm{~mm} \\
\text { induced rms } \mathrm{V} \text { orbit } 10 \mathrm{~mm}\end{array}$ \\
\hline $\begin{array}{l}\text { All three types: } \\
\text { K1 defect } 1 \% \text { al }\end{array}$ & $\begin{array}{c}\mathrm{y}_{\mathrm{rms}}=0.6 r \\
\mathrm{~K}_{0} \text { roll ang } \\
0.983\end{array}$ & $\begin{array}{l}\text { from } V \text {-kickers, } \\
0.02^{\circ} \text { in main bends }\end{array}$ \\
\hline
\end{tabular}

\section{Polarization tracking, including SR}

Energy loss by synchrotron radiation is added in the tracking. The simulation conditions are the following :

- a set of 960 particles are tracked, Gaussian-distributed in huge initial emittances $\epsilon_{\mathrm{x}} / \pi=\epsilon_{\mathrm{x}} / \pi=25 \mu \mathrm{m}$ geometrical at $320 \mathrm{MeV}(9 \mathrm{~mm}$ normalized), and with initial $\mathrm{dp} / \mathrm{p} \in \pm 10^{-3}$ uniform.

- defects of different amounts are considered, this is specified in due place, only one random seed is thrown, no statistics performed in this preliminary approach,

- the acceleration voltage applied is (Fig. 5)

$$
\mathrm{V}(\mathrm{t})=4.4 \sin (2 \pi \mathrm{ft})+8.8 \sin ^{8}(2 \pi \mathrm{ft} / 2), \quad \mathrm{f}=60 \mathrm{~Hz}
$$

- the tracking uses a Monte Carlo SR process [7].

Note : Appendix B addresses benchmarking matters. More is in order obviously, this is postponed to further studies. 

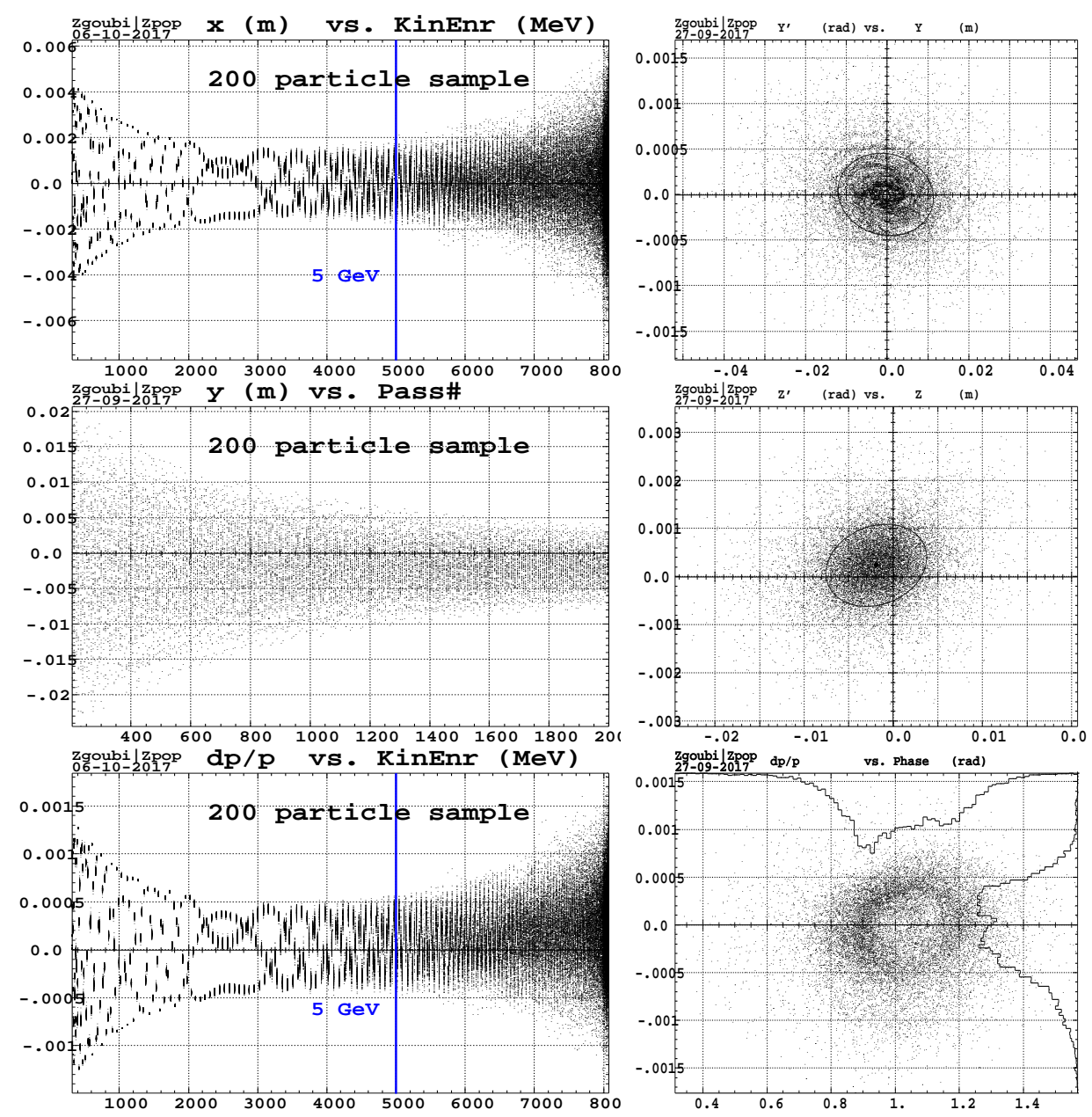

Figure 13: Particle motion from 0.32 to $8 \mathrm{GeV}$. The radial motion is anti-damped, anti-damping time constant $\tau_{\mathrm{x}} \approx 2.77 / \mathrm{E}_{[\mathrm{GeV}]}^{3}$ (Tab. 4).
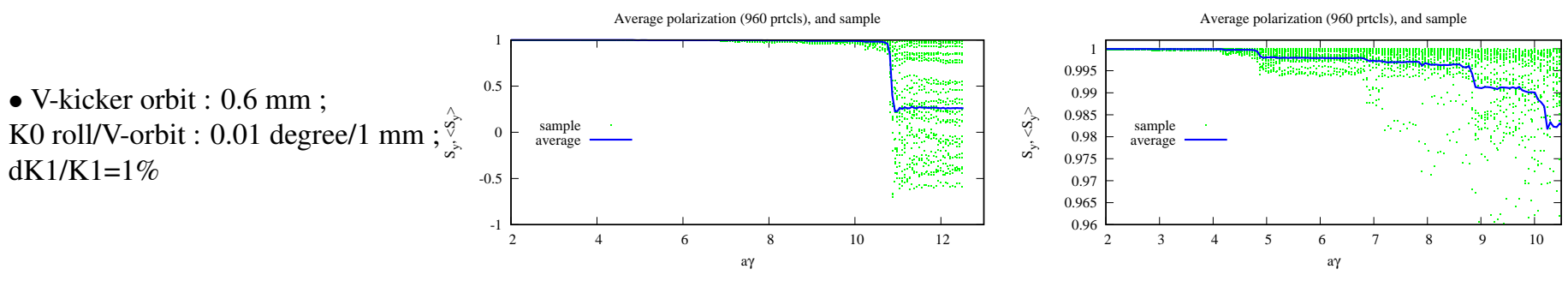

- V-kicker orbit : $1.2 \mathrm{~mm}$; $\mathrm{K} 0$ roll/V-orbit : 0.05 degree $/ 5 \mathrm{~mm} ;$
$\mathrm{dK} 1 / \mathrm{K} 1=1 \%$
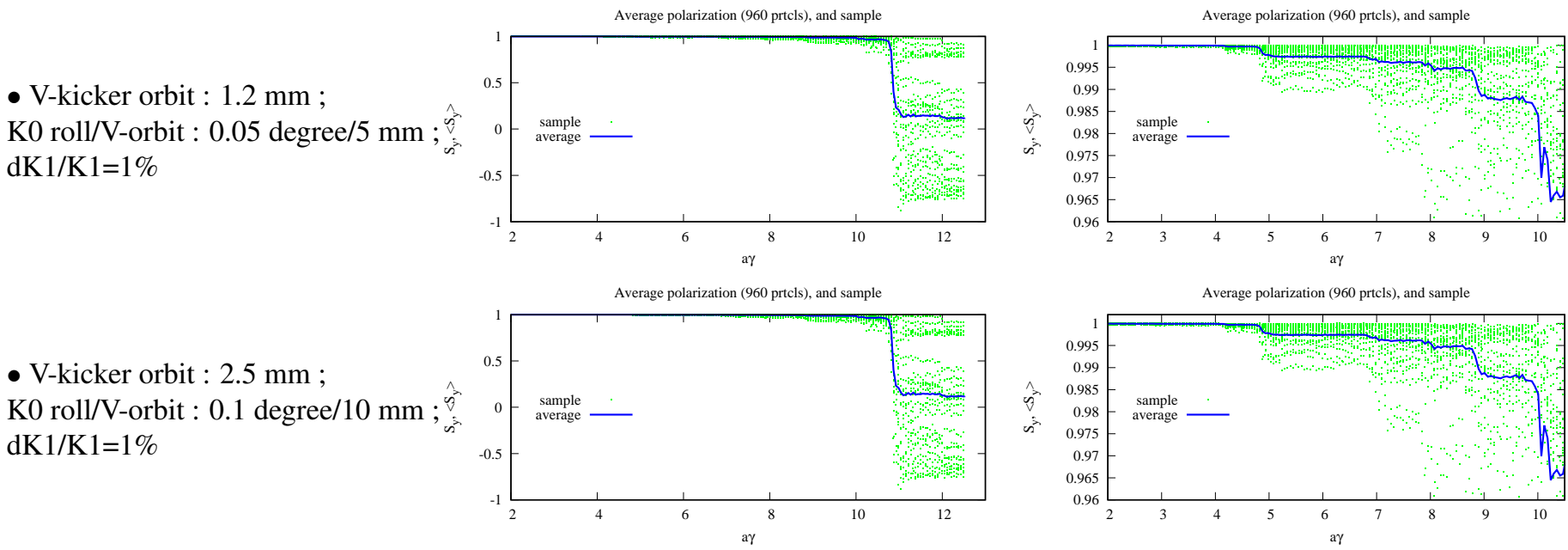

Figure 14: Polarization transport for three different amounts of defects, as detailed in the left column. Green markers : $\mathrm{S}_{\mathrm{y}}$ for a few sample particles. Blue curve : average over 960 particles. Bunch polarization (zoomed in the right col.) at $a \gamma=10.2$ $(4.495 \mathrm{GeV})$, i.e., just upstream of $\mathrm{a} \gamma=\mathrm{Q}_{\mathrm{y}}=10.82(4.768 \mathrm{GeV})$ is, from top to bottom, $98.2 \%, 96.4 \%, 88 \%$. 


\subsection{Beam monitoring}

A first set of figures, upper part of page 11, monitors particle motion over the acceleration cycle. This includes defects, namely, a $0.6 \mathrm{~mm} r m s$ orbit contribution induced by the vertical kickers (as in Sec. 3.2.1), a 1\% rms random gradient error in the bends (as in Sec. 3.1), a 0.05 degree rms random roll angle in the main bends (Sec. 3.2.2).

\subsection{Polarization transmission}

A second set of figures, lower part of page 11, shows the polarization transmission for three different levels of defects :

(i) $0.3 \mathrm{~mm} \mathrm{rms}$ orbit contribution induced by the vertical kickers (as in Sec. 3.2.1), a 0.01 degree roll angle in the main bends (Sec. 3.2.2), a $1 \%$ gradient error in the bends (as in Sec. 3.1),

(ii) $0.6 \mathrm{~mm} \mathrm{rms}$ orbit, 0.05 degree roll, $1 \%$ gradient error,

(ii) $2.5 \mathrm{~mm} \mathrm{rms}$ orbit, 0.1 degree roll. $1 \%$ gradient error,

\section{Comments}

Very preliminary tracking simulations in Cornell RCS using different types of orbit defects, essentially summarizing into Fig. 14 results, indicate that a high degree of polarization transmission is obtained up to the neighboring of the $a \gamma=Q_{y}$ intrinsic resonance in the $4.8 \mathrm{GeV}$ region. Crossing the latter is doable in addition, with proper orbit (harmonic) correction, this is left to further investigations.

In order to proceed toward a feasibility demonstration as a preliminary step toward an experiment at Cornell, the actual synchrotron optics and acceleration ramp parameters have to be clarified, including orbit values and control/corrector schemes on the ramp, as well as the categories of defects to be injected.

More simulations are needed in any case, with realistic RF ramp and orbit defects/correction throughout the acceleration cycle, and statistics over random defect sets, to demonstrate effective end-to-end transmission of bunch polarization up to energies comparable to eRHIC RCS range, namely $5 \sim 10 \mathrm{GeV}$ and possibly higher.

Regarding an experiment at Cornell RCS, in addition :

As stressed earlier (Sec. 1), assessing effectiveness of polarized e-bunch acceleration would require polarimetry in the injector region (source or linac), and at top energy (for instance in CHESS storage ring). It would also require a polarized electron source. These topics are in discussion at present [8].

\section{Acknowledgement}

A substantial amount of computing regarding these simulations has been performed on NERSC [9]. 


\section{Appendix}

\section{A SBEND centering}

Cornell RCS bends are straight axis, parallel face, combined function magnets (gradient is $\mathrm{dB} / \mathrm{dx}$ ).

The closed orbit across the magnet is close to an arc of a circle; due to the gradient it experiences a non-constant dipole field. In zgoubi, this requires introducing an offset of the magnet $(\mathrm{dx})$ such as to ensure proper deviation and identical position, opposite angles, at respectively entrance and exit.

The corresponding MULTIPOL sequence (translation of MADX bend) is given below, for each one of the 6 dipoles of concern.
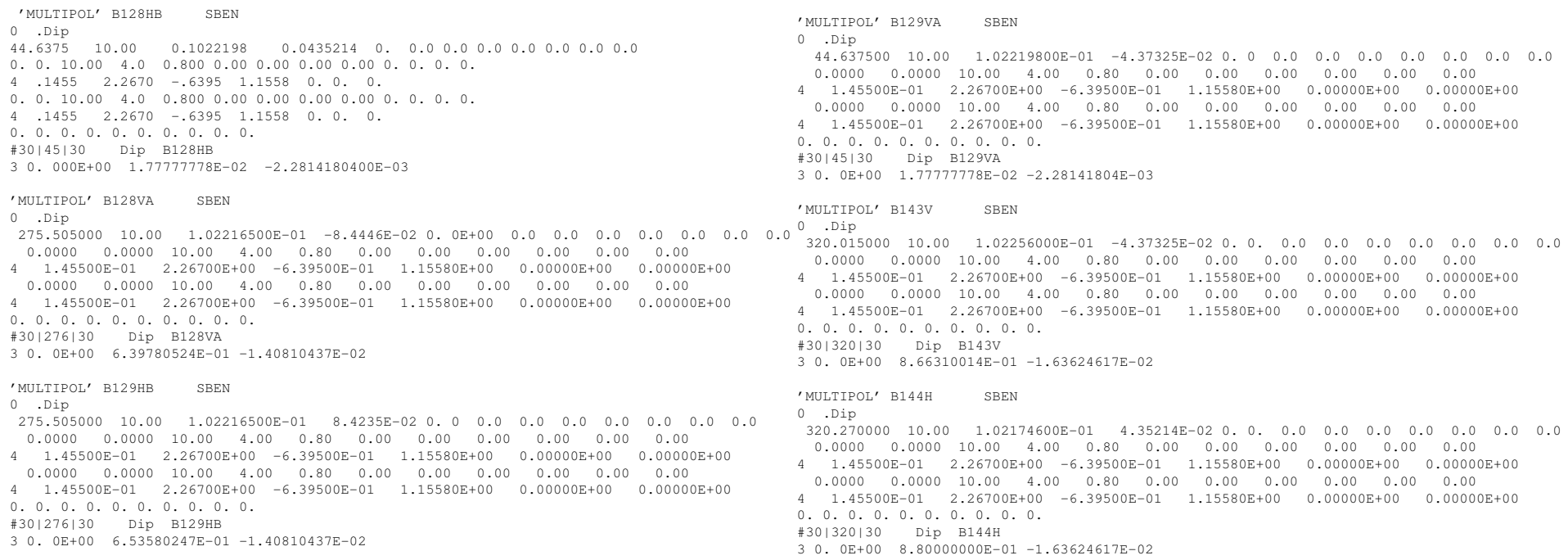

\section{B Benchmarking bunch motion}

Note that there is matter here for benchmarking tracking outcomes against theory. Damping should satisfy, to first order in the invariants,

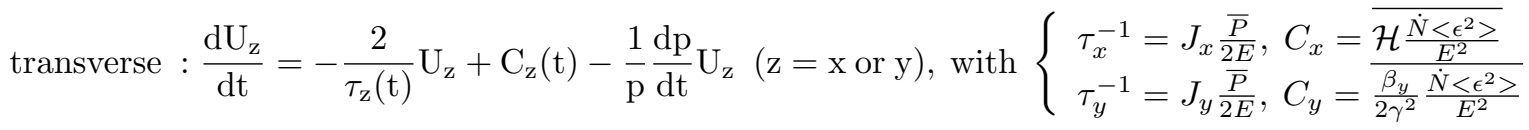

$$
\begin{aligned}
& \text { longitudinal : } \frac{\mathrm{d}(\hat{\Delta \mathrm{E}})^{2}}{\mathrm{dt}}=-\frac{2}{\tau_{1}(\mathrm{t})}(\hat{\Delta \mathrm{E}})^{2}+\left(\dot{\mathrm{N}}<\epsilon^{2}>\right)(\mathrm{t})+\frac{1}{2 \mathrm{E}} \frac{\mathrm{dE}}{\mathrm{dt}}(\hat{\Delta \mathrm{E}})^{2} \text {, with } \tau_{1}^{-1}=\mathrm{J}_{1} \frac{\overline{\mathrm{P}}}{2 \mathrm{E}}
\end{aligned}
$$

which can simply be integrated numerically to check against tracking outcomes (App. C shows the motion). The partition numbers therein satisfy

$$
\mathrm{J}_{\mathrm{x}}=1-\mathcal{D}, \quad \mathrm{J}_{\mathrm{y}}=1, \quad \mathrm{~J}_{1}=2+\mathcal{D}, \quad \text { with } \mathcal{D}=\frac{\overline{\mathrm{D}_{\mathrm{x}}(1-2 \mathrm{n}) / \rho^{3}}}{\overline{\rho^{2}}}=\frac{\mathrm{I}_{4}}{\mathrm{I}_{2}}
$$

These quantities can either be derived from the lattice, or from numerical tracking, for instance,

$$
\begin{array}{rr}
\text { From Mad data, page } 5: & \mathcal{D}=\frac{I_{4}}{I_{2}}=\frac{0.125}{0.0642} \approx 1.95, \text { yielding } \mathrm{J}_{\mathrm{x}} \approx-1 \\
\text { From ray }- \text { tracing }(\text { Tab. } 4): & \tau_{y} / \tau_{x}=-1.3=J_{x} \text { thus } \mathcal{D} \approx 2.3
\end{array}
$$

Note that $\mathcal{D}$ values differ by $15 \%$ depending on the method, the reason has to be found out. There are essentially two different theoretical bending radii around the ring, $97.87 \mathrm{~m}$ and $97.79 \mathrm{~m}$. Computing the energy loss or the quantities above using their average instead makes no significant difference, this is illustrated in Tab. 4 including comparisons with tracking outcomes.

Figures 15, 16 display the evolution of horizontal and vertical emittance with time, respectively

$$
\bar{\epsilon}_{\mathrm{x}}(\mathrm{t})=\epsilon_{\mathrm{x}, 0}\left(\mathrm{e}^{\mathrm{t} /\left|\tau_{\mathrm{x}}\right|}-1\right), \quad \bar{\epsilon}_{\mathrm{y}}(\mathrm{t})=\epsilon_{\mathrm{y}, \mathrm{i}} \mathrm{e}^{-\mathrm{t} / \tau_{\mathrm{y}}}
$$

with $\epsilon_{\mathrm{x}, 0}$ a constant and $\epsilon_{\mathrm{y}, \mathrm{i}}$ an initial value. Tab. 4 displays the numerical values for $\tau_{\mathrm{x}, \mathrm{y}}$ obtained by matching numerical emittances to these theoretical $\bar{\epsilon}_{\mathrm{x}, \mathrm{y}}(\mathrm{t})$ (Fig. 16) and shows in particular that $\tau_{\mathrm{y}[\mathrm{s}]} \approx 2.77 / \mathrm{E}_{[\mathrm{GeV}]}^{3}$ which is consistent with the reported 2.5/ $E^{3}$ in [4, Sec. 18, p. 24]. 
Table 4: Energy loss depending on synchronous energy $\left(E_{s}\right.$, total), as expected from theory taking either an average radius value (col. 2) or taking into account all different radii (col. 3), and as obtained from tracking (col. 4). Cols 5, 7 display the damping times obtained from the tracking, cols. 6,8 show that they satisfy the expected $\tau \propto E_{s}^{-3}$.

\begin{tabular}{|c|c|c|c|c|c|c|c|}
\hline \multirow[t]{3}{*}{$\mathrm{E}_{\mathrm{s}}(\mathrm{GeV})$} & \multicolumn{3}{|c|}{ Energy loss per turn $(\mathrm{MeV})$} & \multirow{2}{*}{\multicolumn{4}{|c|}{$\begin{array}{l}\text { Damping times }\left(\times 10^{-3} \mathrm{~s}\right) \\
\quad(\text { from tracking })^{(b)}\end{array}$}} \\
\hline & \multicolumn{2}{|c|}{ Theoretical $=0.08846 E_{[\mathrm{GeV}]}^{5} / \rho_{[\mathrm{m}]}$} & \multirow[t]{2}{*}{ Monte Carlo ${ }^{(a)}$} & & & & \\
\hline & $<\rho>=97.83$ & Actual rho values & & $-\tau_{\mathrm{x}}$ & $-\tau_{\mathrm{x}} \times \mathrm{E}^{3}$ & $\tau_{\mathrm{y}}$ & $\tau_{\mathrm{y}} \times \mathrm{E}^{3}$ \\
\hline 0.32 & $9.482 \times 10^{-6}$ & $9.482 \times 10^{-6}$ & $9.526 \times 10^{-6}$ & & & & \\
\hline 5 & 0.56516 & 0.56514 & 0.56944 & 16.4 & 2050 & 22.1 & 2.762 \\
\hline 10 & 9.04250 & 9.04225 & 9.09299 & 2.12 & 2120 & 2.77 & 2.770 \\
\hline
\end{tabular}

(a) From $10^{4}$ particles, cumulated energy loss over ring circumference (orbit spiraling is marginal).

(b) 2000 particles, tracked over a few damping times.

\section{Transverse motion at constant energy}

Sample tracking outcomes regarding the evolution of $\mathrm{H}$ and $\mathrm{V}$ emittances at 5 and $10 \mathrm{GeV}$, and actual particle motion.
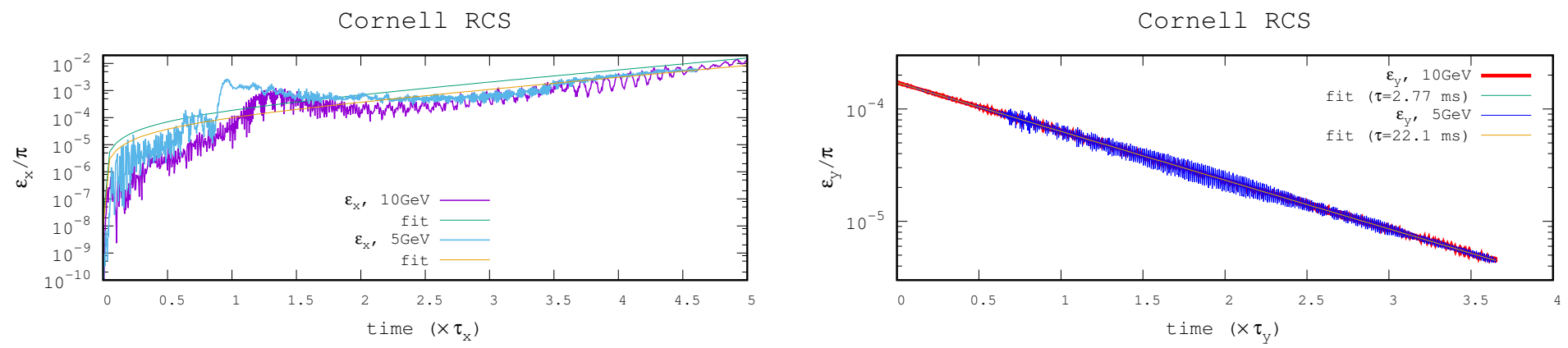

Figure 15: Emittance (a 2000 particle bunch) of anti-damped horizon- Figure 16: Emittance (computed for 2000 particles) of damped vertital motion at 5 and $10 \mathrm{GeV}$. The time, horizontal axis, is in units of cal motion at 5 and $10 \mathrm{GeV}$. The time, horizontal axis, is in units of $\tau_{\mathrm{y}}$, namely, 16.4 and $2.12 \mathrm{~ms}$ at 5 and $10 \mathrm{GeV}$ respectively (Tab. 4). $\tau_{\mathrm{y}}$, namely, 22.1 and $2.77 \mathrm{~ms}$ at 5 and $10 \mathrm{GeV}$ respectively (Tab. 4).

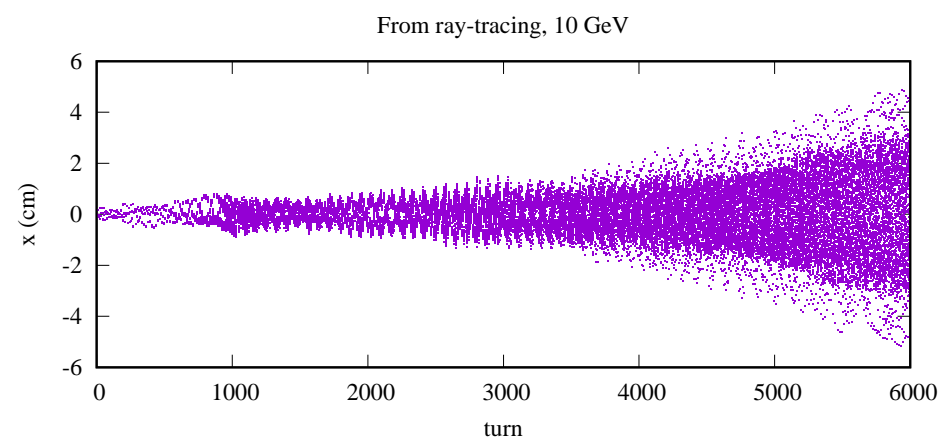

Figure 17: Anti-damped horizontal motion at $10 \mathrm{GeV}$, a few tens of particles displayed.

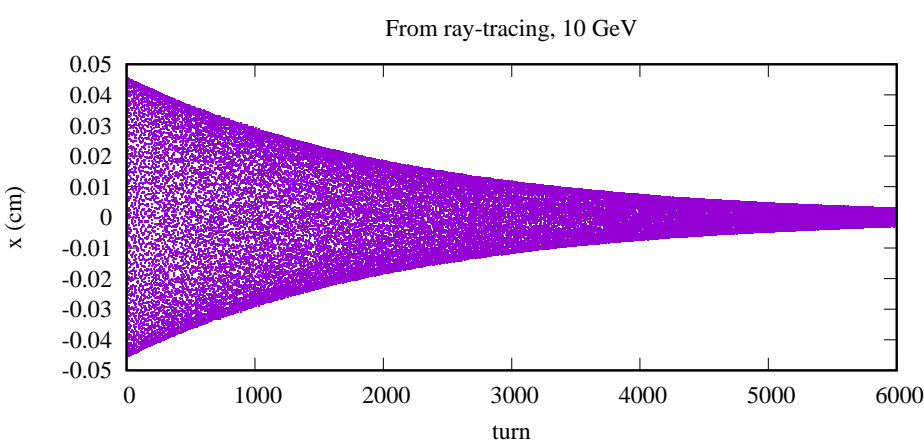

Figure 18: Damped vertical motion at $10 \mathrm{GeV}$, a few tens of particles displayed. 


\section{References}

[1] eRHIC p-CDR, in preparation.

[2] V. Ranjbar et al., EIC Collaboration meeting, BNL, 10-12 Oct. 2017.

[3] "Committee Report for the eRHIC Design Choice Validation Review”, BNL C-AD, April 2017.

[4] R.R. Wilson, The 10 to $20 \mathrm{GeV}$ Cornell electron synchrotron, CS-33, Laboratory of Nuclear Studies, Cornell University, May 1, 1967.

[5] Accelerating system for Cornell $10 \mathrm{GeV}$ electron synchrotron, M. Tigner, IEEE Transactions on Nuclear Science, June 1967.

[6] Performed using Zgoubi. https://zgoubi.sourceforge.io/ZGOUBI_DOCS/Zgoubi.pdf or https://www.osti.gov/scitech/biblio/1062013-zgoubi-users-guide

[7] Simulation of radiation damping in rings, using stepwise ray-tracing methods, F. Méot, JINST 10 T06006 (2015).

[8] A BNL/Cornell/JLab collaboration meeting, discussing a possible polarized e-bunch experiment at Cornell RCS, held since May 2017. Minutes available.

[9] NERSC computing, on web : http://www.nersc.gov/ 